\title{
Voyageurs de la Renaissance, éd. G. HOLTZ, J.-Cl. LABORIE et F. LESTRINGANT
}

\section{Maurizio Busca}

\section{QpenEdition \\ Journals}

\section{Edizione digitale}

URL: https://journals.openedition.org/studifrancesi/22436

DOI: $10.4000 /$ studifrancesi.22436

ISSN: 2421-5856

\section{Editore}

Rosenberg \& Sellier

\section{Edizione cartacea}

Data di pubblicazione: 1 avril 2020

Paginazione: 160-161

ISSN: 0039-2944

\section{Notizia bibliografica digitale}

Maurizio Busca, «Voyageurs de la Renaissance, éd. G. holtz, J.-Cl. LABorie et F. Lestringant», Studi Francesi [Online], 190 (LXIV | I) | 2020, online dal 01 avril 2020, consultato il 03 août 2021. URL: http:// journals.openedition.org/studifrancesi/22436 ; DOI: https://doi.org/10.4000/studifrancesi.22436

Questo documento è stato generato automaticamente il 3 août 2021.

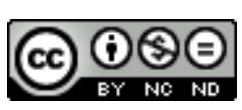

Studi Francesi è distribuita con Licenza Creative Commons Attribuzione - Non commerciale - Non opere derivate 4.0 Internazionale. 


\title{
Voyageurs de la Renaissance, éd. G. HOLTZ, J.-Cl. LABORIE et F. LESTRINGANT
}

\author{
Maurizio Busca
}

\section{NOTIZIA}

Voyageurs de la Renaissance, éd. G. HOLTZ, J.-Cl. LABORIE et F. LESTRINGANT, Paris, Gallimard, 2019, «Folio classique», $576 \mathrm{pp}$.

1 La presente antologia riunisce quarantadue estratti di testi composti da viaggiatori per lo più francesi che, fra la metà del Quattrocento e il primo Seicento, hanno consegnato alla pagina le loro osservazioni sul mondo ottomano (p. I, «La marche turque», pp. 29-102), sull'Africa e sulle Indie orientali (p. II, «La route des Indes», pp. 103-205) e sulle Americhe (p. III, «Le Nouveau Monde», pp. 207-467). Rivolgendosi idealmente ad un pubblico ampio, i curatori hanno modernizzato la grafia e la punteggiatura dei brani in francese (intervenendo talvolta anche sulla sintassi) e hanno fornito in traduzione $i$ testi originariamente redatti in altre lingue, talvolta facendo ricorso a versioni antiche. Ognuno dei passi scelti è presentato da una nota introduttiva, corredato di una bibliografia essenziale e accompagnato da un doppio apparato di note lessicali ed esplicative. Una cronologia delle principali spedizioni esplorative, commerciali e militari condotte nel XVI secolo (pp.471-479) e una snella bibliografia generale (pp. 480-487) completano il dossier critico.

Il volume costituisce un'ottima introduzione, agile e al contempo sostanziosa, alla letteratura di viaggio del Rinascimento. La densa prefazione di Frank Lestringant (pp. 7-24) ben illustra le peculiarità di un corpus particolarmente problematico e percorso da un'irriducibile inquietudine, dove tradizione letteraria e conoscenza esperienziale appaiono spesso inconciliabili e dove le tensioni culturali, sociali e religiose di un'epoca si vedono pienamente riflesse. Gli estratti proposti, inoltre, restituiscono efficacemente la ricchezza e l'eterogeneità di tale corpus, espressione della varietà degli orizzonti culturali e degli interessi degli autori. Questi i testi antologizzati. 
Partie I («La marche turque»): Léon l'Africain (Hasan Al-Wazzan), Description de l'Afrique; Jean Chesneau, Voyage de Paris en Constantinople, celui de Perse, avec le camp du Grand Turc; Pierre Belon, Les observations de plusieurs singularités et choses mémorables; Guillaume Postel, La République des Turcs; Nicolas de Nicolay, Quatre premiers livres des navigations et pérégrinations orientales; Jean Palerne, Pérégrinations. Partie II («La route des Indes»): Vasco de Gama, "Premier voyage aux Indes"; Antonio Pigafetta, Premier voyage autour du monde sur l'escadre de Magellan; Gomes Eanes de Zurara, Chronique de Guinée; Duarte Lopes et Filippo Pigafetta, Relation du Royaume de Congo; Francisco Alvarez, Discours de la navigation de Jean et Raoul Parmentier; Ludovico di Varthema, Les voyages ou Le Viateur; Jan Huygen van Linschoten, Itinéraire; François Xavier, Lettre du Japon, de Cochin; Fernão Mendes Pinto, La Pérégrination. Partie III («Le Nouveau Monde»): Christophe Collomb, Lettre à Luis de Santangel; Amerigo Vespucci, Lettre à Soderini; Pêro Vaz de Caminha, Lettre au Roi Dom Manuel, de la terre de Vera Cruz; Binot Paulmier de Gonneville, Relation authentique; Duarte Pacheco Pereira, Esmeraldo de Situ Orbis; Giovanni da Verrazano, Voyage à la Francesca. «Antilles, Mexique et Pérou»: Hernán Cortés, Cartas y Relaciones; Bernal Diaz del Castillo, Histoire véridique de la conquête de la Nouvelle Espagne; Alvar Nuñez Cabeza de Vaca, Relation et commentaires. «Canada»: Jacques Cartier, Premier et second voyages au Canada; Marc Lescarbot, Histoire de la Nouvelle-France. «Brésil»: Hans Staden, Histoire véritable; André Thevet, Les Singularités de la France Antarctique; Id., Histoire de deux voyages aux Indes Australes et Occidentales; Lettre de Vicente Rodrigues aux pères et frères de Coïmbra; Jean de Léry, Histoire d'un voyage fait en la terre du Brésil; Anthony Knivet, Un aventurier anglais au Brésil. «Floride et Virginie»: Jean Ribault, La complète et Véridique découverte de la Terra Florida; René de Laudonnière, L'histoire notable de la Floride; Copie d'une lettre venant de Floride envoyée à Rouen et depuis au Seigneur d'Everon; Nicolas Le Challeux, Discours de l'histoire de la Floride. "Épilogue»: Capitaine Bruneau de Rivedoux, Histoire véritable de certains voyages périlleux et hasardeux sur la mer; José de Acosta, Du salut des Indiens. 